\title{
The Relationship between Spot and Futures Prices in Brent Oil Crude Market
}

\author{
Mohsen Mehrara ${ }^{a}$, Monire Hamldar ${ }^{b}$ \\ Faculty of Economics, University of Tehran, Kargar-e-shomali, \\ Po Box 14166-6445, Tehran, Iran \\ ${ }^{a, b}$ E-mail address: mmehrara@ut.ac.ir , hamldar@ut.ac.ir
}

\begin{abstract}
This paper investigates the relationship between spot and futures prices in Brent Crude Oil Market using daily data over the period 1990/17/8-2014/11/3. The results of unit root test indicate that both of the spot and futures prices variables are non-stationary. The results of the Johansen cointegration test suggest that there is a long-run relationship between these variables. The dynamic Granger causality captured from the vector error correction model indicates strong bidirectional effects between the spot and futures price of Brent Crude Oil. The coefficient of the ECT and lagged explanatory variables are significant in both equations which indicates that long-run as well as shortrun bidirectional causalities between log of spot and futures price.
\end{abstract}

Keywords: Unit Root; Cointegration; Granger Causality; VECM; Spot and Futures Price of Brent Crude Oil

\section{INTRODUCTION}

In theory, since both futures and spot prices reflect the same aggregate value of the underlying asset and considering that instantaneous arbitrage is possible, futures should neither lead nor lag the spot price.

However, the empirical evidence is diverse, although the majority of studies indicate that futures influence spot prices but not vice versa. The usual rationalization of this result is that the futures prices respond to new information more quickly than spot prices, due to lower transaction costs and flexibility of short selling.

Therefore, both hedgers and speculators will react to the new information by preferring futures rather than spot transactions. Spot prices will react with a lag because spot transactions cannot be executed so quickly (Silvapulle and Moosa, 1999). Furthermore, the price discovery mechanism, as illustrated by Garbade and Silber (1983), supports the hypothesis that futures prices lead spot prices.

The recent empirical evidence on causality is invariably based on the Granger test (Granger, 1969). The conventional approach of testing for Granger causality is to assume a parametric linear, time series model for the conditional mean. Although it requires the linearity assumption this approach is appealing, since the test reduces to determining whether the lags of one variable enter into the equation for another variable. Moreover, tests based on residuals will be sensitive only to causality in the conditional mean while co-variables may influence the conditional distribution of the response in nonlinear ways. Baek and Brock 
(1992) noted that parametric linear Granger causality tests have low power against certain nonlinear alternatives.

This paper investigates the causality between spot and futures prices in Brent Crude Oil during 1990/17/8-2014/11/3. Section 2 discusses the methodology and data. We also present the empirical results of the paper in section 2, and section 3 concludes.

\section{METHODOLOGY AND EMPIRICAL RESULTS}

In this section we use the Granger causality to study the causal relationship between the spot price and futures price. The financial variables used in the model are spot and futures price of Brent Oil. The data series are obtained from Energy Information Agency(EIA). The data are daily from 1990/17/8-2014/11/3.

\section{1. Augmented Dickey-Fuller Unit Root Test}

One of the tests for identifying the existence of unit roots in a data series include that of the Augmented Dickey Fuller (ADF) $(1979,1981)$. So in the first step of the empirical analysis, the Augmented Dickey Fuller unit-root tests have been carried out for the both variables: the spot and futures price of Brent Oil, both in logarithm. The results reported in Table 1, indicate that both of the variables are non-stationary. However, recent contributions to the literature suggest that such tests may incorrectly indicate the existence of a unit root, when in actual fact the series is stationary around a one-time structural break (Zivot and Andrews, 1992; Pahlavani, et al, 2006).

Zivot and Andrews (ZA) (1992) argue that the results of the conventional unit root tests may be reversed by endogenously determining the time of structural breaks. The null hypothesis in the Zivot and Andrews test is a unit root without any exogenous structural change. The alternative hypothesis is a stationary process that allows for a one-time unknown break in intercept and/or slope. Following Zivot and Andrews, we test for a unit root against the alternative of trend stationary process with a structural break both in slope and intercept. Table 1 provides the results.

As in the Augmented Dickey Fuller unit-root test, the estimation results fail to reject the null hypothesis of a unit root for both variables. The same unit root tests have been applied to the first difference of the variables and in all cases we rejected the null hypothesis of unit root. Hence, we maintain the null hypothesis that each variable is integrated of order one or I(1).

Table 1. Unit-root tests of Augmented Dickey Fuller.

\begin{tabular}{|c|c|c|c|c|c|}
\hline \multicolumn{2}{|c|}{ Hypothesis } & \multicolumn{2}{c|}{$\begin{array}{r}\text { Logarithm of Futures Price } \\
\text { (Contract \#1) }\end{array}$} & \multicolumn{2}{c|}{ Logarithm of Spot Price } \\
\hline \multirow{2}{*}{ Constant } & t-statistic & 47.04159 & 0.634012 & 75.25922 & 0.771 \\
\cline { 2 - 6 } & P-value & 0.0001 & 0.8607 & 0.0001 & 0.8265 \\
\hline \multirow{2}{*}{$\begin{array}{c}\text { Constant, Linear } \\
\text { Trend }\end{array}$} & t-statistic & 47.0525 & 3.2567 & 75.26237 & 3.39106 \\
\cline { 2 - 6 } & P-value & 0.000 & 0.0737 & 0.0001 & 0.0526 \\
\hline \multirow{2}{*}{\begin{tabular}{c} 
None \\
\cline { 2 - 6 }
\end{tabular}} & t-statistic & 47.03601 & 0.6949 & 75.25877 & 0.579275 \\
\cline { 2 - 6 } & P-value & 0.0001 & 0.8656 & 0.0001 & 0.8415 \\
\hline
\end{tabular}




\section{2. The Johansen Cointegration Test}

Cointegration test means looking for a stationary long-run relationship between nonstationary variables. It has been introduced for the first time in 1980's by Engle and Granger (1987), Johansen $(1988,1991)$, Johansen and Jeslius $(1990,1992)$ and the others. There are some methods for testing for cointegration the most well-known of which is Johansen test. These test detect two cointegrating vector on the assumption of quadratic deterministic trend.

Table 2. The Johansen cointegration tests

Trend assumption: Quadratic Deterministic Trend

\begin{tabular}{|c|c|c|c|c|}
\hline \multirow{2}{*}{ Null hypothesis } & \multicolumn{2}{|c|}{ Trace } & \multicolumn{2}{c|}{ Max-Eigen } \\
\cline { 2 - 5 } & $\mathrm{p}$-value & Statistic & $\mathrm{p}$-value & Statistic \\
\hline None & 0.0001 & 184.3366 & 0.0001 & 174.1642 \\
\hline At Most 1 & 0.0014 & 10.172 & 0.0014 & 10.1723 \\
\hline
\end{tabular}

\section{3. Granger Causality Tests}

The existence of cointegrating relationship between the spot and futures prices of Brent Crude Oil suggests that there may be long run Granger causality in at least one direction (Hatanaka, 1996). In this section, we test for Granger Causality between log of spot price and $\log$ of futures price.

Cointegration implies that causality exists between the two series but it does not indicate the direction of the causal relationship. The dynamic Granger causality can be captured from the vector error correction model (VECM) derived from the long-run cointegrating relationship (Granger 1988). Engle and Granger (1987) showed that if the two series are cointegrated, the vector-error correction model for the spot price and futures price series can be written as follows:

$$
\begin{aligned}
& \Delta \text { Lspot }=\alpha_{y}+\beta_{R} E C T_{t-1}+\sum_{i=1}^{n} \gamma_{R i} \text { LLfuture }_{t-i}+\sum_{i=1}^{n} \delta_{R i}{ }^{\Delta L s p o t}{ }_{t-i}+\varepsilon_{R t} \\
& \Delta L \text { future }=\alpha_{e}+\beta_{E} E C T_{t-1}+\sum_{i=1}^{n} \gamma_{E i} \Delta \text { Lfuture }_{t-i}+\sum_{i=1}^{n} \delta_{E i} \Delta L s p o t_{t-i}+\varepsilon_{E i}
\end{aligned}
$$

where $\Delta$ is a difference operator; ECT is the lagged error-correction term derived from the long-run cointegrating relationship; The $\beta_{i}(i=y, e)$ are adjustment coefficients; a is long run coefficient or elasticity and the $\varepsilon_{i t} s$ are disturbance terms assumed to be uncorrelated and random with mean zero. Sources of causation can be identified by testing for significance of the coefficients on the lagged variables in Eqs. (1) and (2).

First, by testing $H_{0}: \gamma_{R i}=0$ for all $\mathrm{i}$ in Eq. (1) or $H_{0}: \delta_{E i}=0$ for all $\mathrm{i}$ in Eq. (2), we evaluate Granger weak causality. This can be implemented using a standard F-test. Masih (1996) and Asafu-Adjaye (2000) interpreted the weak Granger causality as 'short run' 
causality in the sense that the dependent variable responds only to short-term shocks to the stochastic environment.

Another possible source of causation is the ECT in Equations. (1) and (2). In other words, through the ECT, an error correction model offers an alternative test of causality (or weak exogeneity of the dependent variable).

The coefficients on the ECTs represent how fast deviations from the long run equilibrium are eliminated following changes in each variable.

For example, if $\beta_{R}$ is zero, then Lspot does not respond to a deviation from the long run equilibrium in the previous period. Indeed $\beta_{R}=0$ or $\beta_{E}=0$ is equivalent to both the Granger non-causality in the long run and the weak exogeneity (Hatanaka, 1996). This can be tested using a simple t-test.

It is also desirable to check whether the two sources of causation are jointly significant, in order to test Granger causality. This can be done by testing the joint hypotheses $H_{0}: \beta_{R}=0$ and $\gamma_{R i}=0$ for all $\mathrm{i}$ in Eq. (1) or $H_{0}: \beta_{E}=0$ and $\delta_{E i}=0$ for all $\mathrm{i}$ in Eq. (2). This is referred to as a strong Granger causality test. The joint test indicates which variable(s) bear the burden of short run adjustment to re-establish long run equilibrium, following a shock to the system (Asafu-Adjaye, 2000). A test of these restrictions can be done using Ftests.

Another concept related to Granger-causality is that of instantaneous causality. Roughly speaking, a variable spot price is said to be instantaneously causal for another time series variable futures price if knowing the value of spot price in the forecast period helps to improve the forecasts of futures price. It turns out, however, that in a bivariate VAR process, this concept reduces to a property of the model residuals.

More precisely, let $\varepsilon_{t}=\left(\varepsilon_{R t}, \varepsilon_{E t}\right)$ be the residual vector of $y_{t}=(\Delta L s p o t, \Delta L$ futures $)$; then, $\Delta L$ spot is not instantaneously causal for $\Delta L$ futures if and only if $\varepsilon_{E t}$ and $\mathrm{u} \varepsilon_{R t}$ are uncorrelated. In turn, $\Delta L$ spot is instantaneously causal for $\Delta L$ futures if and only if $\varepsilon_{R t}$ and $\varepsilon_{E t}$ are correlated. Consequently, the concept is fully symmetric. If $\Delta L s p o t$ is instantaneously causal for $\Delta L$ futures, then $\Delta L$ futures is also instantaneously causal for $\Delta L$ spot . Hence, the concept as such does not specify a causal direction.

The causal direction must be known from other sources. Still, if it is known from other sources that there can only be a causal link between two variables in one direction, it may be useful to check this possibility by considering the correlation between the residuals (Lutkepohl, 2004). The results of the tests on causality are presented in Table 3 . The evidence strongly indicates the bidirectional causality between the log of spot price and the log of futures price. The coefficient of the ECT and lagged explanatory variables are significant in both equations which indicates that long-run as well as short run bidirectional causalities. 
Table 3. Result of causality tests.

\begin{tabular}{|c|c|c|c|c|c|}
\hline \multirow{2}{*}{} & \multicolumn{5}{|c|}{ Source of causation } \\
\cline { 2 - 6 } & \multicolumn{2}{|c|}{ Short-run } & Long-run & \multicolumn{2}{c|}{ Joint (short-run/long-run) } \\
\cline { 2 - 6 } & $\Delta L s p o t$ & $\Delta L f u t u r e$ & $E C T(-1)$ & $\begin{array}{c}\Delta L s p o t, \\
E C T(-1)\end{array}$ & $\begin{array}{c}\Delta L f u t u r e, \\
E C T(-1)\end{array}$ \\
\hline $\begin{array}{c}\text { Null hypothesis } \\
\text { statistics }\end{array}$ & $\begin{array}{c}\chi^{2} \\
\text { statistics }\end{array}$ & t-statistics & $\begin{array}{c}\chi^{2} \\
\text { statistics }\end{array}$ & $\begin{array}{c}\chi^{2} \\
\text { statistics }\end{array}$ \\
\hline $\begin{array}{c}\text { Lspot does not cause } \\
\text { Lfuture }\end{array}$ & 24.36 & - & -2.06 & 7.377 & - \\
\hline p-value & $(0.00)$ & - & $(0.03)$ & $(0.00)$ & 285.5 \\
\hline $\begin{array}{c}\text { Lfuture does not cause } \\
\text { Lspot }\end{array}$ & -244.82 & 6.99 & - & $(0.000)$ \\
\hline p-value & $(0.00)$ & $(0.00)$ & & \\
\hline
\end{tabular}

Notes: the lag length has been chosen based on minimum SC. $\Delta$ denotes series in first difference.

\section{CONCLUSION}

In the present paper we investigated the existence of unit root an then the existence of cointegration. It was shown that the VECM modeling suggested a strong long-run and shortrun bidirectional causalities between the spot and futures prices.

\section{References}

[1] Garbade K.D., Silber W.L., Review of Economics and Statistics 65 (1983) 289-297.

[2] Lien D., Luo X., Journal of Futures Markets 13 (1993) 909-920.

[3] Silvapulle P., Moosa I.A., The Journal of Futures Markets 19 (1999) 175-193.

[4] Abbas Ali Rezaei, International Letters of Social and Humanistic Sciences 23 (2014) $1-20$.

[5] Seyed Reza Seyed-Javadin, Reza Raei, Mohammad Javad Iravani, Mohammad Safari, International Letters of Social and Humanistic Sciences 24 (2014) 45-55.

[6] Farhad Rahbar, Mostafa Sargolzaei, International Letters of Social and Humanistic Sciences 24 (2014) 95-105.

[7] Mohsen Mehrara, Fateme Ghamati, International Letters of Social and Humanistic Sciences 25 (2014) 75-81.

[8] Mohsen Mehrara, Monire Hamldar, International Letters of Social and Humanistic Sciences 26 (2014) 82-87. 